\title{
10. On the dualistic nature of power and (digital) technology in organizing processes
}

\author{
by Attila Bruni ${ }^{*}$,Francesco Miele ${ }^{* *}$, Daniel Pittino ${ }^{* * *}$, \\ Lia Tirabeni ${ }^{* * * *}$
}

\begin{abstract}
The paper focuses on the relationships between power and technology in the field of organization studies, shedding light on the conceptual juxtapositions arousing from the debate.

It discusses the many concepts of power and the relationship between digital technologies and power. Then it focuses on the role of digital technologies with respect to automation processes and control dynamics and deepens the transformations of jobs and professions in relation to digital technologies' adoption.

The contribution calls for overcoming the dualistic nature of debates, so to understand sociality and materiality, power and technology as a form of continuum.
\end{abstract}

\section{Introduction}

This contribution focuses mainly upon the relationship between power and technology in the organization studies field. First, it explores how the concept of power has been understood in sociology and organization theory.

Then, it discusses the relationship between digital technologies and power by particularly showing how the idea of sociomateriality appears particularly apt to focus on the constitutive entanglement of power and digital technologies.

${ }^{*}$ Associate professor at University of Trento.

${ }^{* *}$ Researcher at University of Padova.

*** Assistant professor at University of Udine and associate professor at Jönköping International Business School.

${ }^{* * * *}$ Assistant professor at University of Milano Bicocca.

Studi organizzativi - Special Issue 2020 - Issn 0391-8769, Issn-e 1972-4969 
Thereafter the focus shifts towards an exploration of the role of digital technologies with respect to automation processes and control dynamics.

Finally, it deepens the transformations in jobs and professions in relation to digital technologies adoption since a central role in the debate on the interplay between digital technology and organizing is occupied by the transforming potential on work tasks, jobs and entire professional fields. Accordingly, it shows a tension between constraining and enabling effects arising from the diffusion of digital technologies.

Our contribution highlights how the above debates tend to be polarized in two main stances: optimist or alarmist, or, according to some authors, modernist or postmodernist and critical. Indeed, as recently pointed out by Meyer, Shaupp and Seibt $(2019$, p. 2) in relation to the digitalization in industries, the most of contributions are alarmist or techno-optimist, finally missing that there are «more intricate, and often ambiguous dynamics that happen» and must be taken into account.

Our contribution, by calling attention to the dualistic nature of debates, underlines the need to go beyond it. We argue that in such a challenge the sociomateriality approach can be of great help.

\section{The concept(s) of power in organization studies}

Power is an ambiguous concept generally understood as the influence towards a course of action that an agent would not otherwise undertake (Clegg et al., 2006; Weber, 1978). In sociology and organization theory, theories on power may vary considerably. However, drawing on Hatch and Cunliffe (2013), we can make a first distinction between two prevalent approaches: a managerial-oriented, "modernist" stance, and a critical, "postmodernist" one.

From the one hand, modernist theories on power try to explain how power is allocated within organizations with the purpose of formulating normative suggestions for effectively managing it in the political processes.

We can consider, for example, the work of Crozier and Friedberg (1977). They focused on the different sources and expressions of power and identified four sources of power within organizations: skills, relations between the organization and its environment, communication and information, and organizational rules. An individual source of power derives from the margins of freedom he/she enjoys in relation to the others he/she depends on, so that the actor's power is «a function of the size of the zone of uncertainty that the unpredictability of the actor's conduct enables 
him to control vis-a-vis his partners» (Crozier and Friedberg 1977, p. 34). However, the same source of uncertainty can become an important source of power and profoundly influence an organization's functioning or, on the contrary, can remain unused and less useful within another organization that employs the same technology.

In the modernist view, managerial power is not only useful, but rather necessary to control workers as any organization implies and needs control. Accordingly, control processes help to delineate eccentric behaviors and maintain them compliant to the overall rational project of the organization (Tannenbaum, 1968). This view implies a dualistic conceptualization of power which is understood as something only available to the few in order to control the many. In such a view, managers (the few) exert power over the employees (the many) within organizations mainly through the mechanism of rewards and sanctions (Stanton and Stam, 2002).

From the other hand, postmodernist and critical theorists are interested in how power relations become embedded, for instance, in culture, knowledge, language and ideologies. See for example how Czarniawska and Karnas (1991) understand power as a historical concept: power becomes embedded in the so-called cultural context of organizing, namely a historically formed network of organizational and social processes and systems of values and beliefs (Czarniawska, 1986). Recently, other scholars, drawing on the sensemaking literature, suggest that power can be implicated in actors' interpretations of unfamiliar, unexpected and idiosyncratic events and issues (Schildt et al., 2020).

More in general, critical scholars try to set the stage for inclusive, ethical, and humanistic approaches for decision-making processes as opposite to the ideological and rational project promoted by modernist scholars that favor only the élite. Critical scholars insist on the relational aspects of power. In such a perspective, power is seen as generative, relational, and productive; it is a relationship through which the individuals involved exploit their own resources to influence another's actions (Whitson, 2014).

According to a relational understanding, Lukes (1974) firstly advanced the notion of a «third face of power» arguing that the most effective type of power is not one that can be possessed; rather it operates through a subtle shaping of interests. The most "powerful" type of power is one that influences people without their knowing (Plesner and Husted, 2019).

But power is an ambiguous concept, and scholars underline also that it can be conceived not only in negative terms. Clegg et al. (2006) note that in organizations power generally owns a negative meaning and implies 
coercion and hierarchies, nonetheless it can be a very positive phenomenon. Indeed, power can "empower" because its impact on individuals is not only constraining, but also enabling (Mantere and Vaara, 2008) exactly as the power a teacher has over a student thanks to their role induces compliance that enables the student to learn (Schildt, Mantere and Cornelissen, 2020).

Instead of viewing power as a repressive force, early on Foucault (1977, 1982) conceived power as a productive force that underlies the constitution of knowledge in general. But Foucault (1980) stressed also another crucial, often misunderstood, aspect of power: a shift from the external locus of power to an internal one. He stressed a shift from the concepts of surveillance and control to those of self-surveillance and self-control due to mechanisms of individual internalization. Accordingly, if within a modernist stance power implies the managerial control over workers, critical approaches stress how control can be self-inducted and take the form of self-discipline. As Mackenzie et al. (2020, p. 3) recently highlighted, Foucauldian concepts of power «offer critical viewpoints upon work in neoliberal societies through which individuals are not only targets of power but active in its operation».

Carrying on such ideas further, Zuboff (1988) linked digital technologies, power, and organizing. In Zuboff's view, the informating nature of digital technology can subvert the traditional logic of managerialism since it places knowledge, and thus power, in the hands of workers. In such a frame, managers are forced to find new ways of controlling their employees. As noted by Plesner and Husted (2019, p. 226) «ironically, what makes digital technology so subversive (an excess of data) also provides the grounds for a new type of power that Zuboff refers to as 'panoptic power', the power of surveillance».

\section{Digital technologies, power and sociomaterial practices}

The debate about the consequences that introducing digital technologies may have on power relations in organizations tends to be polarized in two positions (Meyer, Shaupp, and Seibt, 2019; Tirabeni and Miele, 2020; Nielsen, Andersen and Danziger, 2016): an alarmist and an optimistic one. On one hand, some authors suggest that technology may support the existing distribution of power, as individuals, groups, and organizations that are already advantaged in the political process are able to shape the diffusion, design, and use of new technologies in ways enhancing their established interests (Norris and Reddick, 2013). In this vein, the 
introduction of digital technologies in organizations has been seen as a further opportunity for managers to control workers (Nielsen, Andersen and Danziger 2016). On the other hand, scholars suggested that technology may transform pre-existing power relations (Dunleavy et al., 2006) and profoundly change prior power dynamics, reinforcing peer-relations, transforming organisational practices, professional roles and re-allocating responsibilities (Petrakaki, Klecun and Cornford, 2016).

In such a debate, a deterministic view of technology emerges, missing that there are: «more intricate, and often ambiguous, dynamics that happen between total domination and total emancipation» (Meyer, Shaupp and Seibt, 2019, p. 2). In fact, according to a non-deterministic view of technology, power relationships are not imposed by technology; on the contrary, they rely on the ways technology is used, which in their turn may be influenced by various organizational dimensions (e.g. pre-existing cultural backgrounds, information infrastructures, relationships and textures of practices).

Studies adopting a sociomaterial perspective (Barad, 2003; Orlikowski, 2007; Orlikowski and Scott, 2008), for example, have emphasized the interplay between digital technologies and human agency as a driver for change in power distribution within several fields, such as journalism (e.g. Plesner and Raviola, 2016) or healthcare (e.g. Introna, Hajies, and AlHejin, 2019). At the same time, the way censorship is inscripted within search engines (such as Google) highlights power as the result of a complex sociomaterial assemblage.

The concept of sociomateriality derives from the work conducted by Karen Barad (2003) on the work of quantum physicists and takes up that of «material-semiotic» already adopted by Donna Haraway (1993) and by Actor-Network Theory (ANT) (Law, 1986; Callon, 1998). At the basis of both concepts is the idea that reality and action are always the result of an assemblage of matter and meaning, or of what Barad (2003) defines as sociomaterial entanglement: «there is no social that is not also material and no material that is not also social» (Orlikowski, 2007, p. 1437). Hence, the absence of the hyphen between the word "socio" and "material".

Although there are more "weak" and "strong" interpretations of the concept (Jones, 2014), the idea of sociomateriality appears particularly apt to focus on the constitutive entanglement of power and digital technologies (Beverungen et al., 2019). Digital computation "indexes", processes and transforms the world into a set of observations or instructions (Peters, 2016). This is why we need to look at the sociomaterial dimension of the practices through which (digital) technologies and (digital) powers are 
actualized. As Leonardi (2013: 70) notes: «Microsoft Excel has many features that do not change across contexts (materiality). But those features do not automatically calculate modal values in a numerical list (material agency) until some user (with social agency) tells that materiality to do so».

Sociality and materiality are constitutive of each other (Law and Mol, 1994): in organizations, strategies are formed based on the ways people use PowerPoint presentations to share information with one another and routines are both made possible and performed through the use of checklists and protocols (Leonardi et al., 2012). Digital technologies, in particular, seem to deploy what Koch (2003) has termed «the power of default»: although in principle digital technologies could be configured by their users in many different ways, actors are likely to take the short cut of using suggested settings and parameters. In this way, a sociomaterial assemblage is stabilized, emerging as a "normal" pattern of action.

It should be noted that the recent "hype" for digital media in organization studies has somehow re-proposed the issue of the extent to which we can frame the relationship between users and technologies as a symmetrical one. In the Introduction of the recently published Oxford Handbook of Media, Technology and Organization Studies, for example, Beyes, Holt and Pias $(2019$, p. 2) write: «Contrary to a somewhat hyperactive sociology of socio-material association (or actor-networks), we do not assume that each and every actant is symmetrical footing with any other actant, in a merry dance of agencies. As technology, the object in question organizes or affords a certain process of organizing. It can thus be configured as technological medium that enables and shapes, perhaps even in some ways conditions or determines, organization». Media are seen as $a$ priori of organization, in that they «configure (power) relations that are inbuilt into the devices and apparatuses of organizational life» (Beyes et al., 2019: 1).

In this way, the recurring debates regarding the more or less deterministic effects of technologies in organization somehow testifies how technology remains a contested domain in organization studies, whose conceptualization and consequences are still under discussion.

\section{Digital technologies, automation and control}

Digital technologies can not only re-shape organizational processes, but they can also play a central role in these ones, partially or totally replacing human action. The debate concerning the consequences of automated 
production on the working and organizing processes has undoubtedly dominated social sciences since their early start. In particular, over the last three decades, the continuous and massive technological innovation has stimulated the emergence of polarized positions. Jeremy Rifkin, in his wellknown work The end of work (1995), predicted a disastrous impact of automation on worldwide unemployment, hoping for a consequent growth of a third sector that would create new jobs with government support. A few years later, among the possible scenarios connected with automation, Ulrich Beck (2001) outlines the so-called "brazilianization" of the western societies, characterized by the reduction of social security and salaries, the increase of social inequalities, the individualization of employment relationships and the intensification of precariousness. In the following years, on the one hand various authors tried to define the macro-effect of automation (e.g. Standing, 2014); on the other hand, organization studies, dialoguing with other research fields such as Science and Technologies Studies (STS) (Bijker et al., 1987/2007), have shaded light on the ways trough which technologies have re-shaped everyday working life. In particular, recently, a great attention has been paid to the role of algorithms in elaborating data and providing feedbacks that influence organizational processes (Kellogg et al., 2020; Giardullo and Miele, forthcoming).

The debate about algorithms exemplifies the current focal points in social sciences regarding automation. A first focal point concerns the possibility that algorithms substitute human actors in production processes. If some authors keep an optimistic position underlining that automation, also when it is sustained by artificial intelligence, can produce unemployment only in sectors dominated by manual and unskilled jobs (Autor and Dorn, 2013), others point out that the processes of substitution is much wider (Brynjolfsson and McAfee, 2011). Algorithms can analyze a great amount of data concerning production flows, giving recommendation to workers or taking decisions about the organization of work. These kinds of activities, traditionally carried out by middle management, can be now enacted by new technologies and fully automatized in some of its parts (Delfanti, 2019).

Consequently, a second focal point concerns the influence of automation on control dynamics. Recently, Kellogg, Valentine and Christin (2020), through an extended literature review, delineate six kinds of "algorithmic control". For the authors employers can use algorithms in the following ways: to help direct workers by restricting the available courses of actions and by recommending some choices rather than others; to evaluate workers by recording data concerning working performances and rating them; and 
to discipline workers by rewarding workers or by replacing them with other ones.

Among the contributions focused on the relationship between automation and control, some describe the introduction of algorithms in the workplace as a neo-Taylorist trend where working bodies are increasingly regulated through the imposition of productivity standards (Moore and Robinson, 2016). Others, on the contrary, claim that algorithms often gather data about the psychophysical conditions of workers and their daily habits, so to support companies in the creation of organizational rules and standards of productivity more aligned with the "natural" biological temporalities of workers (O’Neill, 2017).

Third, some studies focus on the forms of resistance enacted by workers against the automation processes enabled by algorithms. Akhtar and Moore (2016) underline the importance of trade union for limiting and regulating the diffusion of wearable devices aimed at collecting and analyzing data concerning working performances. Leonardi and colleagues (2020) focuses on resistance practices enacted by food delivery riders against the top-down control exercised by the management through technologies for tracking workers. In this case, technologies act both as devices of control which through algorithms define and monitor the organization of work, and tools which can be used by workers for subverting power dynamics, gathering data useful for labor claims. This topic needs to be investigated further, focusing on the so-called algoactivism practices enacted by workers (Kellogg et al., 2020), overcoming the deterministic view of technology in which users are conceived as passive agents. This research direction is relevant to understand how people interact with technologies in unexpected ways, thus reducing the possibility that these devices could become tools for controlling the lives of workers in pervasive ways while at the same time ensuring that the advantages connected with them are protected (Tirabeni and Miele, 2020).

\section{Digital technologies and the transformations of jobs and professions}

Further narrowing down the focus on the human work, a central role in the debate on the interplay between digital technology and organizing is occupied by the transforming potential on work tasks, jobs and entire professional fields. In general, we observe a tension between constraining and enabling effects arising from the diffusion of digital technologies, 
otherwise expressed as automation versus augmentation paradox (Raisch and Krakowski, 2020).

As emphasized in the previous section, digitalization in its different expressions has the potential to radically change the conditions for influence, autonomy and engagement in the accomplishment of work tasks. For example, it has been highlighted that technological devices, equipped with artificial intelligence are capable of independent decision-making and formulate judgements, that challenge the autonomy of employees (Blazejevski and Walker, 2018).

Such situations trigger responses from employees which may entail job crafting behaviors. Job crafting refers to «the physical and cognitive changes individuals make in the task or relational boundaries of their work» (Wrzesniewski and Dutton, 2001, p. 179). Thus, employees, instead of been passive recipients of (technology driven) job design have the possibility to alter task content and work setting, to derive different meanings in their jobs (Berg et al., 2010).

In line with the sociomaterial perspective, job crafting, in the interplay between digital technologies and organizing, fosters active technology appropriation practices (Orlikowski and Scott, 2008) such as that the use of technology and its implications in job characteristics depend on the interpretations of its users regarding meanings and functionalities attributed to technology (Blazejevski and Walker, 2018; Orlikowski, 2000). This means also that a digital technology that is used as an enabling tool in one setting, can be used as a control function in another (Mauléon, 2017; Mauléon and Spante, 2016). What creates transparency and/or open flow of information (Beyes and Pias, 2018) can equally facilitate information manipulation and distortion (Franco-Santos and Otley, 2018). This "malleable" core of digital technologies in organizing supports the wellknown argument that workers' participation and know-how are necessary conditions for the effective design and introduction of technologies in organizations (Ciborra and Lanzara, 1988).

Across the functional boundaries of jobs and organizations, digital technologies interact also with the features of professional fields and expertise (e.g. Stein et al., 2019). As proposed by Plesner and Raviola (2016), technology and humans (along with other elements) co-create the processes of reorganization of professions. For example, Plesner and Raviola (2016) studying the journalist profession, observe that increasing digitalization of news work does not seem to make a particular group or individual more powerful, but rather reallocate the power across a constellation of people, objects and relationships, stabilized around certain 
technical devices. On the other hand, Beane (2019), observing the surgical practice, conclude that, due to the diffusion of robots and intelligent machines, experts are increasingly distanced from their work, and the opportunities of training on the job and the related apprenticeship relationships that are typical of many professions are changing or disappearing.

Overall, since a profession can be seen as a «sociomaterial network» (Law, 1992), digital technologies definitely fosters a change in key features and concepts of professional work and expertise. This, in turn, promotes a redistribution of power into new configurations of professional communities.

\section{Concluding remarks}

For many years, the debate about power and digital technologies has been characterized by a polarization between domination and emancipation (see Meyer et al., 2019). Both positions are marked by a deterministic view, in which the intrinsic properties and functionalities of technologies are seen as drivers of sociocultural changes in the workplace (Leonardi and Jackson, 2004), and workers only have space for deciding whether to accept or refuse them.

The utopian and dystopian scenarios about power relations and technological change are certainly fascinating and have become part of the collective imaginary but, at the same time, they reduce the complexities and ambiguities of the phenomenon at stake.

If, on the one hand, it is evident that digital technologies have been often designed and used for achieving specific goals and interests, on the other hand various studies show that the interplay between technology and organizing processes has often unpredictable outcomes. In this scenario, the attempts of consolidating power asymmetries through the design and adoption of new technologies are often mitigated and/or hindered by appropriation dynamics highly influenced by different dimensions (such as organizational and professional cultures, users' interests and needs, preexisting organizational practices and routines).

In their enactment, technologies become the situ where a continuous dialogue between control and resistance, domination and emancipation, constriction and enablement takes place. Overcoming a dualistic approach could be of help in understanding these dichotomies in terms of a continuum, so as for the relationship between power and technology. 
Attila Bruni et al.

\section{References}

Autor D.H., Dorn D. (2013). "The Growth of Low-skill Service Jobs and the Polarization of the US Labor Market". American Economic Review, 103(5): 1553-97.

Beane M. (2019). "Learning to Work with Intelligent Machines". Harvard Business Review, 97(5): 140-148.

Beck U. (2000). The Brave New World of Work. Cambridge: Polity Press.

Beverungen A., Beyes T., Conrad L. (2019). "The Organizational Powers of (Digital) Media", Organization, 26(5): 621-635.

Beyes T., Pias C. (2018). Secrecy, Transparency and Non-knowledge. In: Bernard A., Koch M., Leeker M. (eds.). Non-Knowledge and Digital Cultures. Luneburg: Meson Press.

Blazejewski S.,Walker E.M. (2018). "Digitalization in Retail Work: Coping With Stress Through Job Crafting", Management Revue, 29(1): 79-100.

Brynjolfsson E. and McAfee A. (2011), Race Against the Machine: How the Digital Revolution is Accelerating Innovation, Driving Productivity, and Irreversibly Transforming Employment and the Economy. Lexington (MA): Digital Frontier Press.

Butera F. (2015). Automation. In: Wright J. (ed.). International Encyclopedia of Social and Behavioral Sciences, $2^{\text {nd }}$ edition, Oxford Elsevier.

Butera, F., Koehler E., Di Martino V. (1989). Technological Development and the Improvement of Living and Working Conditions. London and Bruxelles: Kogan Page \& EEC Official Publications.

Ciborra U. C., Lanzara G. F. (1988). “Designing New Systems in Action”. Paper presented at the Conference Joint Design of Technology Organization and People Growth, Venice, October 12-14, republished in this book (Capter 4).

Clegg S., Courpasson D., Phillips N. (2006). Power and Organizations. London: SAGE Publications.

Crozier M., Friedberg E. (1977). L'acteur et le système. Paris: Editions du Seuil.

Czarniawska B. (1986) "The Management of Meaning in The Polish Crisis". Journal of Management Studies, pp. 313-331.

Czarniawska B., Kranas, G. (1991). "Power in the Eyes of the Innocent (Students talk on power in organizations)". Scandinavian Journal of Management, 7(1): 41-60.

Delfanti A. (2019). "Machinic Dispossession and Augmented Despotism: Digital Work in an Amazon Warehouse". New Media \& Society, 1-7, online first December 2, 2019.

Foucault M. (1977). Discipline and Punish: The Birth of the Prison. New York: Pantheon.

Foucault M. (1980). Power/Knowledge: Selected Interviews and Other Writings by Michel Foucault, 1972-77. New York: Pantheon.

Foucault M. (1982). "The Subject and Power". Critical Inquiry, 8(4): 777-795.

Franco-Santos M., Otely D. (2018). "Reviewing and Theorizing the Unintended Consequences of Performance Management Systems". International Journal of Management Review, 20(3).

Giardullo P., Miele F. (forthcoming) "L'organizzazione algoritmica: tecnologia, performance e automazione. In: Marini D., Setiffi F. (eds.). La Grammatica del 4.0. Società ed economia nei processi di digitalizzazione. Milano: Guerini.

Hatch M.J., Cunliffe A.L. (2013). Organization Theory: Modern, Symbolic and Postmodern Perspectives. Oxford: Oxford University Press.

Introna L.D., Hayes N., Al-Hejin Z. (2019). "The Negotiated Order and Electronic Patient Records: A Sociomaterial Perspective”. Journal of Information Technology, 34(4): 333349. 
Irani L. (2015). "Difference and Dependence among Digital Workers: The Case of Amazon Mechanical Turk". South Atlantic Quarterly, 114(1): 225-234.

Kellogg K.C., Valentine M.A. and Christin A. (2020). "Algorithms at Work: The New Contested Terrain of Control". Academy of Management Annals, 14(1): 366-410.

Leonardi P.M., Jackson M.H. (2004). "Technological Determinism and Discursive Closure in Organizational Mergers". Journal of Organizational Change Management, 17(6): 615-631.

Leonardi D., Murgia A., Armano E. (2020). Piattaforme digitali e forme di resistenza della soggettività precaria: un'inchiesta sul lavoro gratuito e la mobilitazione dei riders di Foodora a Torino. In: Armano E. (ed.). Pratiche di inchiesta e conricerca oggi. Verona: Ombre Corte.

Lukes S. (1974). Power: A radical view. London: Macmillan.

Mackenzie E., McGovern T., Small A., Hicks C., Scurry T. (2020). "Are They Out to Get Us? Power and the 'Recognition' of the Subject Through a 'Lean' Work Regime". Organization Studies, 0170840620912708, online first.

Mantere S., Vaara E. (2008). "On the Problem of Participation in Strategy: A Critical Discursive Perspective". Organization Science, 19: 341-358.

Mauléon C. (2017). "Risky Business or Support? And for Who? Investigating the Enactment of Digital Management Control Systems in Swedish Primary Schools", 26 ${ }^{\text {th }}$ Annual Conference/Meeting of the Society for Risk Analysis - Europe (SRA-E), Lisbon, June 19-21.

Mauléon C., Spante M. (2016). "On the Intended and Unintended Consequences of the Enactment of Digital Management Control Systems in Swedish Schools". IFIP WG 8.2 Working Conference, December 9-10, Dublin, Ireland.

Means A.J. (2017). "Education for a Post-Work Future: Automation, Precarity, and Stagnation". Knowledge Cultures, 5(1): 21-40.

Meyer U., Shaupp S., Seibt D. (2019), Digitalization in Industry: Between Domination and Emancipation. London and New York: Palgrave.

Moore P., Robinson A. (2016). "The Quantified Self: What Counts in the Neoliberal Workplace”. New Media \& Society, 18(11): 2774-2792.

Nielsen J.A., Andersen K.N., Danziger J.N. (2016). "The Power Reinforcement Framework Revisited: Mobile Technology and Management Control in Home Care". Information. Communication \& Society, 19(2): 160-177.

Norris D.F., Reddick C.G. (2013) "Local e-Government in the United States: Transformation or Incremental Change?" Public Administration Review, 73(1): 165-175.

O'Neill C. (2017). "Taylorism, the European Science of Work, and the Quantified Self at Work". Science, Technology, \& Human Values, 42(4): 600-621.

Orlikowski W.J. (2000). "Using Technology and Constituting Structures: A Practice Lens for Studying Technology in Organizations". Organization Science, 11(4): 404-428.

Orlikowski W.J., Scott S.V. (2008). "Sociomateriality: Challenging the Separation of Technology, Work and Organization". The Academy of Management Annals, 2(1): 433474.

Petrakak, D., Klecun E., Cornford T. (2016). "Changes in Healthcare Professional Work Afforded by Technology: the Introduction of a National Electronic Patient Record in an English Hospital". Organization, 23(2): 206-226.

Plesner U., Raviola E. (2016). "Digital Technologies and a Changing Profession". Journal of Organizational Change Management, 29(7): 1044-1065.

Plesner U., Husted E. (2019). Digital Organizing. London: Red Globe Press.

Rifkin J. (1995). The End of Work. New York: Putnam. 
Attila Bruni et al.

Shaba E., Guerci M., Gilardi S., Bartezzaghi E. (2019). "Industry 4.0 Technologies and Organizational Design - Evidence from 15 Italian Cases". Studi Organizzativi, 1.

Schildt H., Mantere S., Cornelissen J. (2020). "Power in Sensemaking Processes". Organization Studies, 41(2): 241-265.

Stanton J.M., Stam K.R. (2003). "Information Technology, Privacy, and Power within Organizations: A View from Boundary Theory and Social Exchange Perspectives". Surveillance \& Society, 1: 152-190.

Stein M.K., Wagner E.L., Tierney P., Newell S., Galliers R.D. (2019). "Datification and the Pursuit of Meaningfulness in Work". Journal of Management Studies, 56(3): 685-717.

Tannenbaum A.S. (1968). Control in Organizations. New York: McGraw-Hill.

Tirabeni L., Miele F. (2020). "Tecnologie digitali e potere nelle organizzazioni: dinamiche di controllo ed effetto "contraccolpo". Studi Organizzativi, 2020(1), forthcoming.

Weber M. (1978). Economy and Society. Berkeley (CA): University of California Press.

Whitson J.R. (2014). "Foucault's Fitbit: Governance and Gamification". The Gameful World: Approaches, Issues, Applications, pp. 339-358.

Wrzesniewski A., Dutton J.E. (2001). "Crafting a Job: Revisioning Employees as Active Crafters of Their Work". Academy of Management Review, 26: 179-201.

Zuboff S. (1988). In the Age of the Smart Machine. New York: Basic Book.

Zuboff S. (2019). The Age of Surveillance Capitalism. New York: PublicAffairs. 